\title{
Interfacial heat transfer during hot metal forming operations assuming scale failure effects
}

\author{
M. Krzyzanowski ${ }^{1,2}$ and J.H. Beynon ${ }^{3}$ \\ ${ }^{1}$ AGH University of Science and Technology, Faculty of Metals Engineering and Industrial \\ Computer Science, Mickiewicza 30, 30-059 Krakow, Poland; \\ ${ }^{2}$ The University of Sheffield, Department of Materials Science and Engineering, Hadfield \\ Building, Mappin Street, Sheffield S1 3JD, UK \\ ${ }^{3}$ The University of Adelaide, Faculty of Engineering, Computer \& Mathematical Sciences, \\ Adelaide, South Australia, 5005, Australia
}

\begin{abstract}
Analysis of real contact area and thermal resistance combined with experimentally derived interfacial heat transfer coefficient values, led to the development of an advanced finite element based model to simulate the heat transfer at the oxidised tool-workpiece interface during hot steel rolling. An extensive progress review and building on the Sellars 1990's core assumptions are discussed. Today, oxide scale failure is predicted taking into account the main physical phenomena such as stress-directed diffusion, fracture and adhesion of the oxide scale. The separation loads within the scale metal/system are measured during testing. They are sensitive to the chemical composition of steel. The assumption of several parallel heat flow systems at the roll-stock interface remains the core model for today's research.
\end{abstract}

\section{Introduction}

Knowledge of heat transfer along with friction is vital to the understanding and operation of metal forming processes. The contact conditions in metal forming processes are, to a certain extent, specific to the particular operation, and certainly very diverse. The toolmetal contact often involves large sliding lengths on which high pressures, sliding speeds and temperatures may be maintained together with plastic deformation. The plastic deformation coupled with lubrication, failure of oxide layers, creation of reactive metallic surfaces, and the constant renewal of one of the factors affecting the contact at the tool-workpiece interface, is typical for metal forming. Contact pressures can range from $1 \mathrm{MPa}$ to a few 10 $\mathrm{MPa}$ in sheet forming processes, to a few GPa in hard metal rolling or wire drawing. Speeds vary between a few $\mu \mathrm{m} / \mathrm{s}$ (superplastic processing) to tens of $\mathrm{m} / \mathrm{s}$ (high speed drawing, turning or thin strip rolling). Surface temperatures are in the range between $0^{\circ} \mathrm{C}$ and $300^{\circ} \mathrm{C}$ in cold forming due to self heating by plastic deformation, and up to $500^{\circ} \mathrm{C}, 1300^{\circ} \mathrm{C}$ or even $2000^{\circ} \mathrm{C}$ in hot forming, depending on whether aluminium alloys, steels or refractory metals are considered [1]. The effect of these severe contact conditions is emphasised when there are high values of the aspect ratio of contact surface area to deformed volume (e.g. contact length / characteristic thickness in the rolling of flat products).

Mathematical modelling is now extensively used for optimisation of the deformation during the processing of metallic materials. Precisely determined boundary conditions are essential for prediction accuracy of the models. There are many parameters and variables affecting surface interactions [2]. Process parameters include the temperature, speed, reduction, stiffness and dynamic response of the equipment. In rolling, for instance, among the parameters that influence the interactions are the work roll and the back-up roll dimensions, their hardness, magnitude and direction of the surface roughness, cooling 
systems, lubricant delivery and the location of nozzles. The mechanical properties of the rolls and the work piece, including their resistance to deformation, all contribute here. The contributions of surface parameters, such as the chemical reactivity, the tendency to adsorb molecules from the environment, the adsorption of water vapour and oxygen, as well as surface energy, need to be taken into consideration. The nature of oxide scale formation and failure during deformation, the chemical composition of the scale and underlying metal, the adhesion between the scale and the metal surfaces in direct contact must all be taken into account. Lubrication also significantly affects the interface interactions. The chemical composition of the lubricant, the additives and their concentration in the base oil, the molecular chain length, density, viscosity and its dependence on both temperature and pressure, all should be precisely described. If emulsions are used, the composition, the emulsifier and the droplet dimensions are important. The difficulties of making laboratory measurements, combined with the complexity of events at the tool-stock interface, result in a wide range of reported values for the IHTC, Table 1 [3].

Table 1. Measured interface heat transfer coefficient (IHTC) between roll and stock for the hot rolling of steel and aluminium [after 3]

\begin{tabular}{|c|c|c|c|}
\hline \multicolumn{2}{|c|}{ Steel } & \multicolumn{2}{|c|}{ Aluminium } \\
\hline IHTC, $\mathrm{kW} / \mathrm{m}^{2} \mathrm{~K}$ & Reference & IHTC, $\mathrm{kW} / \mathrm{m}^{2} \mathrm{~K}$ & Reference \\
\hline $10-50$ & {$[4]$} & $2-20$ & {$[14]$} \\
15 & {$[5]$} & $5-50$ & {$[15]$} \\
$15-20$ & {$[6]$} & $10-260$ & {$[16]$} \\
$19-22$ & {$[7]$} & $18-38$ & {$[17]$} \\
$100-350$ & {$[8]$} & $23-81$ & {$[18]$} \\
$200-450$ & {$[9]$} & 200 & {$[19]$} \\
$8-25$ & {$[10]$} & 18 & {$[20]$} \\
20 & {$[11,12]$} & $40-75$ & {$[21]$} \\
20 and 40 & {$[13]$} & $1-15$ & {$[22]$} \\
$18-50$ & {$[27]$} & 400 & {$[23]$} \\
\hline
\end{tabular}

Despite all this complexity in the behaviour at the interface, it is common to represent heat transfer or friction as simple coefficients. This is done because only a limited accuracy of prediction is needed, or the required calculation is not overly sensitive to heat transfer and friction, or because the details of the interface are not well understood, so more detailed information is simply not available. There are many circumstances, however, where the success of a mathematical model depends on the appropriate formulation of the boundary conditions, which could be as sophisticated as the model itself. Of course, reasonable choices are necessary to achieve desirable precision. Including all of the above-mentioned complexities into a single mathematical model describing dependence of these two parameters is highly impractical. The model should take into consideration the most important dependencies that affect the tribological system. The parameters of the contact surfaces in hot rolling can include, for instance, the strip and roll roughness, and the thickness of the oxide scale. When lubricants are used, the viscosity and its dependence on the temperature and the pressure are taken into consideration. The concentration of the oil in the water and the droplet dimensions are considered when emulsions are applied, as in the cold rolling of steel strips.

The following sections consider heat transfer in metal forming operations, providing guidance on the evaluation of the interfacial heat transfer coefficient (IHTC) during hot metal forming operations based on variety of experimental observations of oxide scale behaviour, analysis of real contact area and thermal resistance, combined with experimentally derived IHTC values, which led to a physical model of the heat transfer at the oxidised tool- 
workpiece interface developed by Prof. C.M. Sellars and his collaborators in the 1990s. Not surprisingly, given Sellars' track record, the main model assumption remains the core model for today's research into more accurate representation of actual interface conditions. Considering the several parallel heat flow systems at the roll-stock interface as the main assumption, an advanced FE based model has been developed by his collaborators in the following years. The model has been used in this work for numerical evaluation of the interfacial heat transfer during hot metal forming operations assuming complexity of scale deformation and failure effects.

\section{Review of IHTC model representation developed in the 1990s}

The interface heat transfer coefficient $h_{o}$ (IHTC) is used to quantify the resistance of an interface to the transfer of heat, usually from hot workpiece to cool tool. It is commonly defined by the equation $q=h_{o}\left(T_{2}-T_{1}\right)$, in which $T_{1}$ and $T_{2}$ are the temperatures on either side of the interface, and $q$ is the heat flux per unit area across the interface. The absence of detailed insight and a lack of fundamental understanding about the mechanism of heat transfer at a moving interface has led most modellers to assume an average, constant value of the heat transfer coefficient.

The contacting points between two surfaces serve as paths of lower resistance for heat flow in comparison to adjacent regions where heat transfer occurs across air gaps [24]. It has been assumed that the link between friction and heat transfer at the interface is the fraction of the total area, $\varepsilon_{A}$, the area that is in direct contact. The real contact area depends on both the interfacial pressure, $p$, and the shear strength, $k_{\text {shear }}$, in the real contact zone:

$$
p=\frac{m_{c} \varepsilon_{A} k_{\text {shear }}}{\mu}
$$

where $m_{c}$ is an empirical constant within the range of 0 to 1 and $\mu$ is the friction coefficient at the interface [25]. Observations made through pilot mill tests on a 316L austenitic stainless steel shown that the variation in IHTC with reduction, rolling speed and lubrication could be explained on the basis of the influence of these rolling parameters on fractional contact area [26]. The observed increase in the IHTC during rolling was explained by the increase in pressure at the roll stock interface that led to an increase in the real area of contact between two surfaces. The influence of rolling reduction, rolling temperature, roll speed, roll and workpiece mechanical properties and surface roughness can be related to their effect on roll pressure. It has been found that the mean IHTC is linearly related to mean pressure (Fig. 1) [28]. This relationship can be used in industrial rolling to determine the magnitude of the IHTC from an estimate of the rolling load. The estimations exhibited that the heat losses to the work rolls during the early passes in hot rolling can be more than $30 \%$ of the total, showing the importance of accurately characterizing the IHTC in the roll bite.

An additional thermal resistance between the roll surface and the workpiece is introduced by the application of lubricant or the presence of oxide scale. In many cases, such as during hot strip rolling, with large reduction and low rolling temperature, the oxide will be unable to deform plastically with the deformation of the rolled stock and through-thickness cracks will appear orientated mostly perpendicular to the rolling direction. These cracks will allow extrusion of fresh hot metal through the gaps within the scale under the pressure in the roll gap. As a consequence of such metal extrusion, direct contact between the relatively cold roll and the hot metal can occur. This type of scale behaviour has been noticed during the hot rolling of both aluminium [29] and steel [30]. Based on the experimental observations of oxide scale behaviour, analysis of real contact area and thermal resistance, combined with experimentally derived IHTC values, a physical model was developed to represent heat transfer during hot rolling of steel [31]. As suggested by Li and Sellars, the interface heat 
transfer within the roll gap consists of two parallel heat flow systems: through the oxide

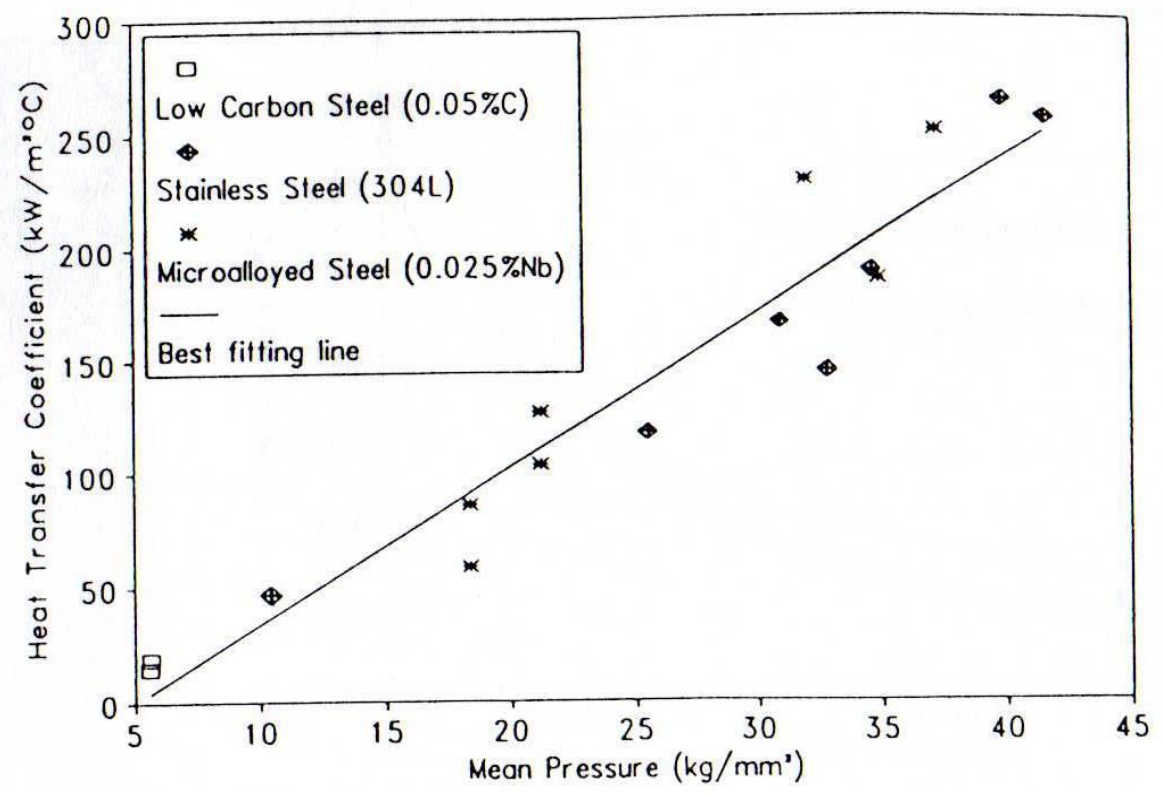

Fig. 1 Relationship between the mean roll pressure and the mean heat transfer coefficient during hot rolling of low carbon, stainless and microalloyed steel [28].

scale - a "two-layer zone", and directly between the roll/fresh metal interface, a "one layer zone", representing the total thermal resistance over the entire apparent contact area by the following equation:

$$
\frac{A_{a}}{R_{e}}=\frac{A_{s}}{R_{e 1}}+\frac{A_{o x}}{R_{e 2}}
$$

where $A_{a}, A_{s}$ and $A_{o x}$ are the overall apparent contact area, and the apparent areas occupied by the extruded fresh steel and by the oxide scales in the roll gap, respectively, and $R_{e}$ is the thermal resistance of the various interfaces.

Then, the effective IHTC, $C_{e}$, can be derived from eq. (2) as

$$
C_{e}=C_{e 1} \alpha_{s}+C_{e 2}\left(1-\alpha_{s}\right)
$$

where $C_{e 1}$ and $C_{e 2}$ are the heat transfer coefficients for the "one layer" and "two layer" zones, respectively. The term $\alpha_{s}$ is the area fraction of the gaps formed from the through-thickness cracks at the interface and filled with fresh metal and is defined as $\alpha_{s}=A_{s} / A_{a}$. In order to obtain the effective IHTC for the entire rolling pass, it is therefore necessary to obtain not only the HTC components for the individual contact zones and thermal barriers, but also to know the mean area fraction of the fresh steel in the roll gap. At that stage of understanding the micro events within the oxide scale metal system, the mean area fraction of the fresh steel extruded through the gaps within the oxide scale was estimated using the following consideration. First, a mean rolling reduction $e_{m}$ is determined thus:

$$
e_{m}=\frac{1}{l} \int_{0}^{l} e_{x} d x=\frac{1}{l} \int_{0}^{l}\left(1-\frac{h_{x}}{h_{0 \text { slab }}}\right) d x
$$

where $l$ is the horizontally projected length of the contact arc determined approximately by $l=\sqrt{\Delta h_{\text {slab }} R}$, and $h_{x}$ is the instantaneous thickness of the slab at the coordinate $x$ of the deformation zone: 


$$
h_{x}=h_{1}+2 R\left[1-\sqrt{1-\left(\frac{x}{R}\right)^{2}}\right] .
$$

Substituting eq. (5) into eq. (4) and integrating yield

$$
e_{m}=\Delta h_{\text {slab }}\left(\frac{2}{3 h_{0 \text { slab }}}+\frac{1}{8 R}\right) \text {. }
$$

Thus, the mean slab thickness corresponding to the mean reduction is defined as $h_{m}=h_{o}$ slab $(1$ $-e_{m}$ ) and volume of the deformation zone $V$ can be determined as $V=l h_{m} b_{m}$, where $b_{m}$ is the mean width of the slab in the deformation zone. Assuming volume constancy of the slab during rolling, the mean area fractions of the scale layer $\alpha_{o x}$ and fresh steel $\alpha_{s}$ in the deformation zone can be determined correspondingly as

and

$$
\alpha_{o x}=1-e_{m}=1-\Delta h_{\text {slab }}\left(\frac{2}{3 h_{\text {oslab }}}+\frac{1}{8 R}\right)
$$

$$
\alpha_{s}=1-\alpha_{o x}=\Delta h_{\text {slab }}\left(\frac{2}{3 h_{\text {oslab }}}+\frac{1}{8 R}\right)
$$

where $\Delta h_{\text {slab }}$ is the absolute reduction in the thickness, $h_{o}$ slab is the initial slab thickness and $R$ is the roll radius [31]. Thus, the effective IHTC depends on HTCs for the individual contact zones and thermal barriers:

$$
C_{e}=C_{e 1} \alpha_{s}+\frac{C_{o x} C_{b 2}}{C_{o x}+C_{b 2}}\left(1-\alpha_{s}\right)
$$

where $C_{b 2}$ is the HTC for the partial contact at the "two layer zone", usually called contact conductance, and $C_{o x}$ is the HTC through the oxide scale. The coefficient $C_{o x}$ was approximately obtained for the given oxide scale thickness $\delta_{o x}$ and the scale thermal conductivity $k_{o x}$ using the following equation:

$$
C_{o x}=\frac{k_{o x}}{\delta_{o x}}
$$

No systematic analysis appears to have been conducted for quantitative variations of the contact conductance with surface, interface and deformation conditions during metal forming operations. It was assumed that, in addition to the surface roughness and thermal conductivity of two contacting solids under normal static contact conditions, the contact conductance is related to the apparent contact pressure, $p_{a}$, and the hardness of the softer contacting material, $H V$, [32-34]. This relationship and also the relationship between the degree of real contact and the dimensionless contact pressure obtained on the basis of experimental measurements and mathematical analysis $[35,36]$ led to establishment of the exponential relationship between the contact conductance and the contact pressure during hot rolling [31]. The same contact and heat transfer states at the scale layer/tool interface were assumed for forging and rolling. Accordingly, the contact conductance for a "two-layer zone" $C_{b 2}$ during hot steel rolling can be calculated by using the following equation that was developed earlier for hot forging of steel:

$$
C_{b 2}=A \frac{\lambda_{h 2}}{R_{a}}\left[1-\exp \left(-0.3 \frac{p_{a}}{H V_{o x}}\right)\right]^{B}
$$

where $A$ and $B$ are empirical constants. For plain carbon steel, for instance, they are assumed to be $0.4 \times 10^{-3}$ and 0.392 respectively. $R_{a}$ is the roll surface roughness. $\lambda_{h 2}$ is the harmonic 
mean of the thermal conductivity of the oxide scale $\lambda_{o x}$ and the steel roll $\lambda_{r}$ and is determined by

$$
\frac{1}{\lambda_{h 2}}=\left(\frac{1}{\lambda_{r}}+\frac{1}{\lambda_{o x}}\right) / 2
$$

The oxide scale grown on low carbon steels can be considered as a brittle material at elevated temperatures up to $800^{\circ} \mathrm{C}$ and its relevant behaviour also depends on the strain rate. Vickers hardness measurements can cause cracks in the oxide layer, so only measurements in the middle of the oxide layer are possible. The Vickers hardness of the oxide scale, $H V_{o x}$, was assumed to vary with the surface temperature of the oxide scale $T_{\text {oxs }}$ according to the following equation developed on the basis of interpolation of the available experimental data [37]:

$$
H V_{o x}=7075-538 T_{\text {oxs }} \quad\left(293 \mathrm{~K} \leq T_{\text {oxs }} \leq 1273 \mathrm{~K}\right)
$$

For a case of low pressure, the equation (5) is replaced by the simpler version:

$$
C_{b 2}=A \frac{\lambda_{h 2}}{R_{a}}\left(0.3 \frac{p_{a}}{H V_{o x}}\right)^{B} .
$$

For the rolling conditions where the initial rolling temperature is around $1000^{\circ} \mathrm{C}$, the scale thickness is within the $25-700 \mu \mathrm{m}$ range, the rolling reduction is between 10 and $50 \%$ and the corresponding average rolling pressure is between 130 and $200 \mathrm{MPa}$, the contact conductance of a "one layer zone" is calculated using the same equations (eq. 11 and 14) where the constants $A$ and $B$ are set to 0.405 and 1.5 respectively, and the parameter $\lambda_{h 2}$ is replaced by $\lambda_{h l}$. The parameter $\lambda_{h l}$ is the harmonic mean of the thermal conductivity of the roll material, $\lambda_{r}$, and the specimen material, $\lambda_{s}$, and is determined by $1 / \lambda_{h l}=\left(1 / \lambda_{r}+1 / \lambda_{s}\right) / 2$. $H V_{s}$ is the Vickers hardness of the fresh steel specimen.

The developed modelling approach successfully demonstrated that the IHTC decreases dramatically once the scale thickness increases because of the relatively poor thermal conductivity of the oxide scale. At the same time, the application of the model allowed for explanation the major reasons why the IHTC increases rapidly with rolling reduction (Fig 2). This was physically consistent with the variation of the real contact area and the high contact conductance in the fresh steel zone that dominated the overall high values of the heat transfer coefficient at the interface during steel rolling, even though the area fraction of the fresh steel zone is less than that of oxide scale for rolling passes with reduction less than $50 \%$. 


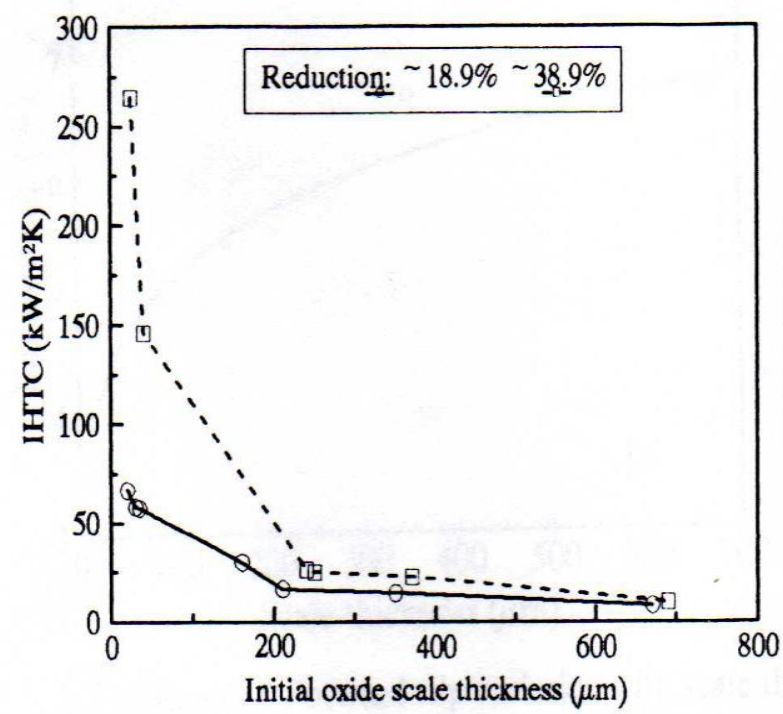

$\mathbf{a}$

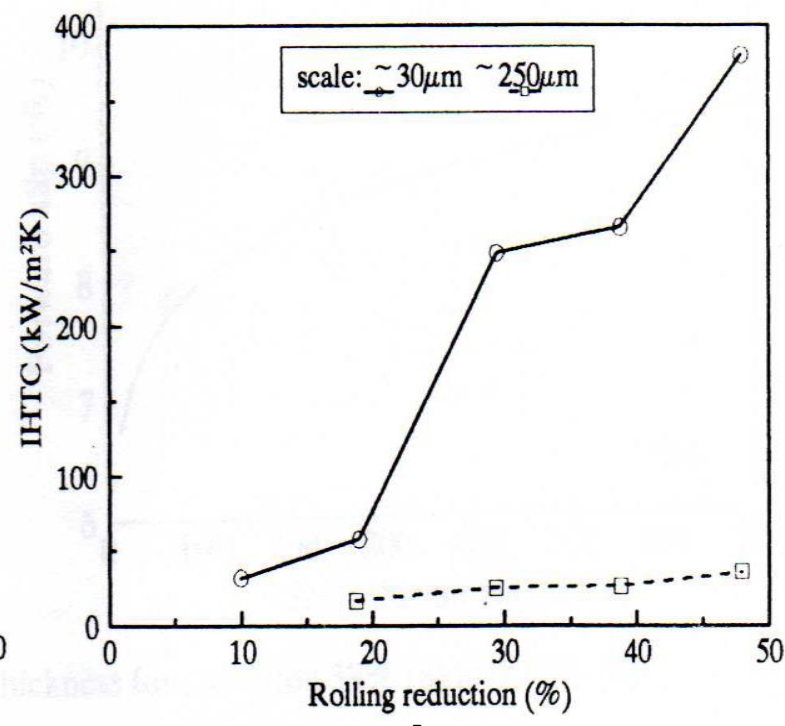

b

Fig. 2 The IHTC during steel hot rolling predicted for the different scale thickness (a) and rolling reduction (b) at initial temperature about $1000^{\circ} \mathrm{C}[31]$.

\section{A physically-based FE oxide scale model considering scale failure effects}

The oxide scale model is usually a meso-part of a more complex multilevel FE model $[38,39]$. The model can be included into and run simultaneously with a macro model representing either a technological operation or a testing procedure. The thickness of the secondary oxide scale, usually about $10-100 \mu \mathrm{m}$, is relatively small with respect to the macro model. The oxide scale model has the capacity to include very fine features such as multi-layer scale, voids or a complicated profile of the scale/metal interface (Fig. 3).
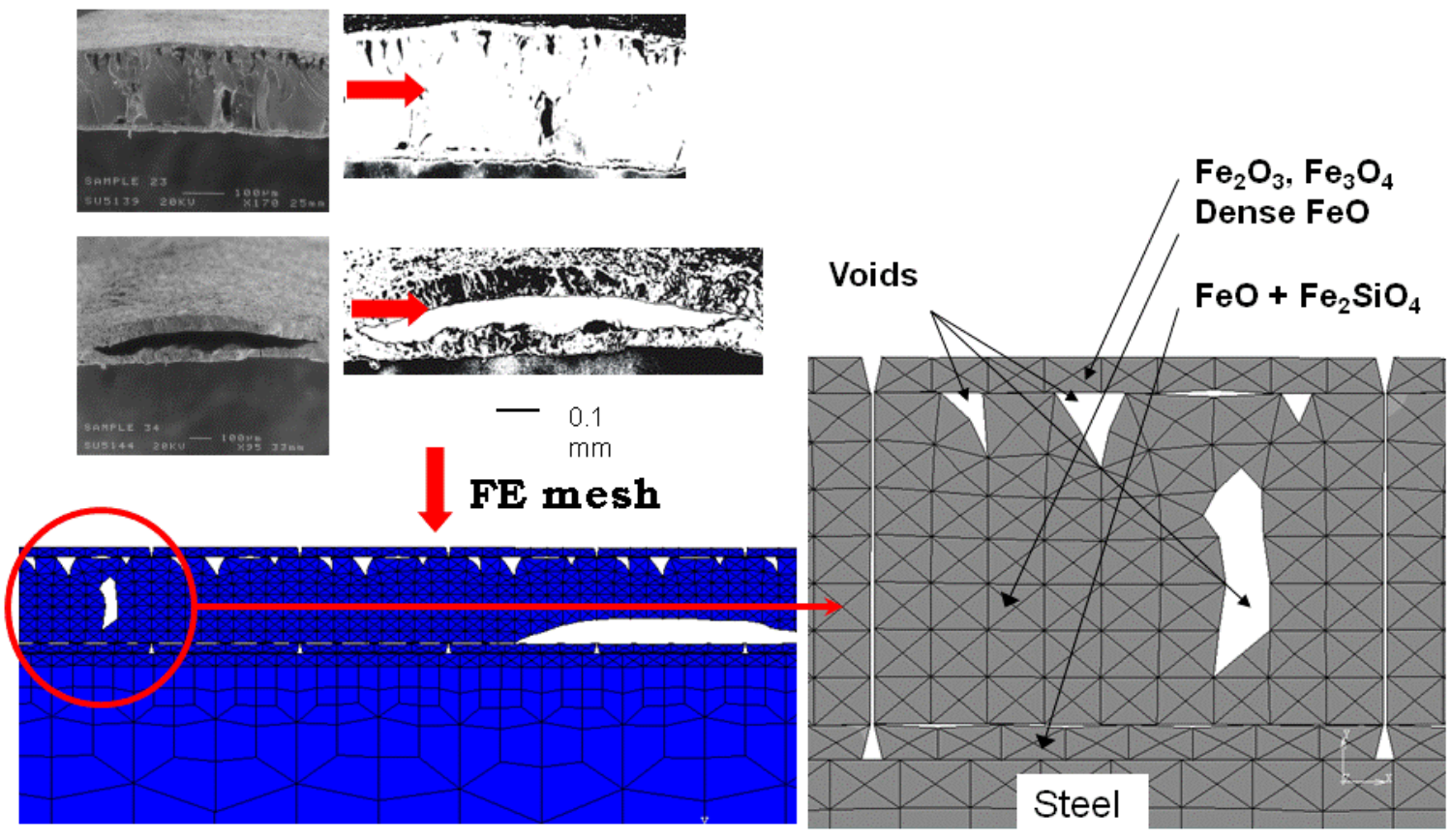

Fig. 3 Schematic representation of the oxide scale FE model set up 
The finite elements should have similar sizes at the contact regions and the increment load should be adequate to the element sizes being in contact so as to avoid the numerical obstacles. It becomes difficult to satisfy the above criteria in a single model. Hence, corresponding linking of modelling scales is a necessary stage for prediction of scale behaviour during modelling of both mechanical testing and technological operations. The oxide scale is simulated as comprising numerous scale fragments joined together to form a scale layer, covering the representative raft length. To be able to reflect the real crack pattern observed during the hot rolling pass, the length of each oxide scale fragment is chosen to be less than the smallest spacing of cracks observed in the experiments. The predicted crack spacing should be insensitive to the sizes of the scale fragments. They are chosen randomly, enabling prediction of representative crack spacing and distribution of cracks along the length of the raft due to both longitudinal tension and contact with the roll. Oxide scale failure is predicted by taking into account the main physical phenomena such as stress-directed diffusion, fracture and adhesion of the oxide scale, strain, strain rate and temperature (Table 1). The main mathematical assumptions of the model related to oxide scale are presented in Table 2. The other relevant details of the model can be found elsewhere $[39,40,48]$.

Table 1. Properties of oxide scale and scale/metal interface used for calculation [after 39]

\begin{tabular}{|c|c|c|}
\hline Parameter & Function & Ref. \\
\hline Density, $\mathrm{kg} / \mathrm{m}^{3}$ & $\rho=5.7 \times 10^{3}$ & Ranta et al., 1993 \\
\hline \multirow[t]{2}{*}{ Specific Heat Capacity, J/kg deg } & $\begin{array}{l}\mathrm{c}_{\mathrm{p}}=674.959+0.297 * \mathrm{~T}-4.367 * 10^{-} \\
5 * \mathrm{~T}\end{array}$ & Ranta et al., 1993 \\
\hline & for $\mathrm{T} \in 600-1100^{\circ} \mathrm{C}$ & \\
\hline Thermal Conductivity, W/mK & $\begin{array}{l}\lambda=1+7.833^{*} 10^{-4 *} \mathrm{~T} \\
\text { for } \mathrm{T} \in 600-1200^{\circ} \mathrm{C}\end{array}$ & Ranta et al., 1993 \\
\hline Young's Modulus, GPa & $\begin{array}{l}\mathrm{E}=\mathrm{E}_{\mathrm{ox}}^{\mathrm{o}}(1+\mathrm{n}(\mathrm{T}-25)) \\
\mathrm{n}=-4.7 \times 10^{-4} ; \mathrm{E}_{\mathrm{ox}}^{\mathrm{o}}=240 \mathrm{GPa}\end{array}$ & Morrel, 1987 \\
\hline Poisson's Ratio & $v=0.3$ & $\begin{array}{l}\text { Robertson and } \\
\text { Manning, } 1990\end{array}$ \\
\hline $\begin{array}{l}\text { Heat transfer coefficient at oxide/metal } \\
\text { interface, } \mathrm{W} / \mathrm{m}^{2} \mathrm{~K}\end{array}$ & $\alpha=30000$ & $\begin{array}{l}\text { Pietrzyk and } \\
\text { Lenard, } 1991\end{array}$ \\
\hline $\begin{array}{l}\text { Surface diffusion coefficient times } \\
\text { effective surface thickness, } \mathrm{m}^{3} / \mathrm{s}\end{array}$ & $\begin{array}{l}\delta_{\mathrm{S}} \mathrm{D}_{\mathrm{S}}=\delta_{\mathrm{S}} \mathrm{D}_{\mathrm{oS}} \exp \left(-\mathrm{Q}_{\mathrm{S}} / \mathrm{RT}\right) \\
\delta_{\mathrm{S}} \mathrm{D}_{\mathrm{oS}}=1.10^{*} 10^{-10} \mathrm{~m}^{3} / \mathrm{s} ; \mathrm{Q}_{\mathrm{S}}=220 \\
\mathrm{~kJ} / \mathrm{mole}\end{array}$ & $\begin{array}{l}\text { Swinkels and } \\
\text { Ashby, } 1981\end{array}$ \\
\hline $\begin{array}{l}\text { Volume (lattice) diffusion coefficient, } \\
\mathrm{m}^{2} / \mathrm{s}\end{array}$ & $\begin{array}{l}\mathrm{D}_{\mathrm{v}}=\mathrm{D}_{\mathrm{ov}} \exp \left(-\mathrm{Q}_{\mathrm{v}} / \mathrm{RT}\right) \\
\mathrm{D}_{\mathrm{ov}}=1.80 * 10^{-4} \mathrm{~m}^{2} / \mathrm{s} ; \mathrm{Qv}_{\mathrm{v}}=159 \\
\mathrm{~kJ} / \mathrm{mole}\end{array}$ & $\begin{array}{l}\text { Swinkels and } \\
\text { Ashby, } 1981\end{array}$ \\
\hline Stress intensity factor, $\mathrm{MN} \mathrm{m}^{-3 / 2}$ & $\begin{array}{l}\mathrm{K}=\mathrm{a}_{0}+\mathrm{a}_{1} \mathrm{~T}+\mathrm{a}_{2} \mathrm{~T}^{2}+\mathrm{a}_{3} \mathrm{~T}^{3}+\mathrm{a}_{4} \mathrm{~T}^{4}+\mathrm{a}_{5} \mathrm{~T}^{5} \\
\text { for } 20-820^{\circ} \mathrm{C} \\
\mathrm{a}_{0}=1.425 ; \quad \mathrm{a}_{1}=-8.897 * 10^{-3} ; \\
\mathrm{a}_{2}=-8.21^{*} 10^{-5} ; \quad \mathrm{a}_{3}=3.176^{*} 10^{-7} ; \\
\mathrm{a}_{4}=-5.455^{*} 10^{-10} ; \quad \mathrm{a}_{5}=3.437 * 10^{-13}\end{array}$ & $\begin{array}{c}\text { Hancock and } \\
\text { Nicholls, } 1988\end{array}$ \\
\hline
\end{tabular}


Table 2. Oxide scale model assumptions [after 39]

\begin{tabular}{|c|c|c|}
\hline Assumption & Equation & Reference \\
\hline $\begin{array}{l}\text { Stress-directed diffusion of metal atoms round } \\
\text { interface irregularities controls the rate of } \\
\text { viscous scale sliding }\end{array}$ & $v_{\text {rel }}=\frac{1}{\eta} \tau$ & Riedel, 1982 \\
\hline $\begin{array}{l}\text { Dislocation creep in addition to diffusional } \\
\text { flow of atoms can circumvent interface } \\
\text { irregularities }\end{array}$ & $v_{\text {rel }}=\frac{1}{\eta}|\tau|^{k-1} \tau$ & Riedel, 1982 \\
\hline $\begin{array}{l}\text { Critical strain for through-thickness crack } \\
\text { depends on fracture surface energy, } \\
\text { Young's modulus, the shape and position } \\
\text { of the void, the composite void size }\end{array}$ & $\varepsilon_{c}=\sqrt{\frac{2 \gamma}{F^{2} \pi E c}}$ & Schütze, 1995 \\
\hline $\begin{array}{l}\text { The viscosity coefficient depends on the } \\
\text { temperature, atomic volume, the diffusion } \\
\text { coefficients, the interface roughness }\end{array}$ & $\eta=\frac{\bar{k} \bar{T} p^{2}}{8 \Omega\left(\delta D_{s}+\lambda D_{V} / 4 \pi\right)}$ & Raj and Ashby, 1971 \\
\hline
\end{tabular}

It was assumed that spalling of the scale could occur along the surface of lowest energy release rate, which can be either within the scale or along the scale/metal interface. A flaw will continue to grow under a stress, if its energy release rate $G$ exceeds the critical energy release rate $G_{c r}$. The availability of experimental data exhibited that through-thickness cracking is an essentially brittle process of unstable crack propagation for the majority of cases. It favoured the assumption of linear elastic fracture mechanics for the model that is acceptable for prediction of scale failure for such cases. Assuming the opening of the through-scale crack due to applied tension loading perpendicular to the crack faces (tensile mode), the critical failure strain $\varepsilon_{c r}$ may be used as a criterion for a through-thickness crack occurring. Tangential viscous sliding of the oxide scale on the metal surface is allowed, arising from the shear stress $\tau$ transmitted from the specimen to the scale in a manner analogous to grain-boundary sliding in high-temperature creep. Tangential viscous sliding of the oxide scale over the metal surface due to the shear stress transmitted from the steel is allowed when the scale and the metal surface are adherent. This kind of viscous sliding is different to frictional sliding of the separated scale fragment when separation stresses are exceeded.

In some cases, steel oxides can show both brittle failure at temperatures below about $800^{\circ} \mathrm{C}$ and signs of ductile fracture at higher temperatures. At high strain rates the failure can become brittle even at high temperatures. Experimental observation of the ductile fracture within the oxide sale favours the important conclusion that the model should be able to accommodate both types of failure. For the former, the critical strain for failure is implemented into the model, while the J-integral is used as a parameter corresponding to the strain energy release rate for consideration of ductile scale failure. Path independence of the J-integral can be proved for non-elastic material behaviour. Provided that the actual elasticplastic material behaviour resembles this non-linear elastic behaviour, the J-integral can also be used to evaluate the stress and strain field near the cracks in elastic-plastic material. Determination of the crack length is based on increment number and deactivation of the separation forces based on the crack length and J-integral value. It has been assumed that no- 
singularity modelling near the crack tip is applicable, with a quarter-point node technique and only one contour for the J-integral specified for each interface. The derivatives of elements of the inverse Jacobian $\mathrm{J}^{-1}$ and of the determinant of the Jacobian $[\mathrm{J}]$ are only considered in the applied virtual crack extension method.

$$
\delta W^{e}=\int_{V^{o}}\left(W \delta|J|+\sigma_{i j} \delta J_{j k}^{-1} \frac{\partial u_{i}}{\partial \eta_{k}}[J]\right) d V^{0},
$$

where the symbols have their usual meaning. The MSC/MARC commercial finite element code is used to simulate metal/scale flow, heat transfer, viscous sliding and failure of the oxide scale during hot rolling, assuming the plane strain condition. The release of nodes is organized with user-defined subroutines in such way that the crack length is determined based on the increment number then, according to crack length, the boundary conditions are deactivated by calling a routine for a specific node number.

Fig. 4 illustrates the gap patterns typically formed in the oxide scale at entry into the roll gap and within the roll gap. The gaps have different lengths because of their different origin. Some relatively big gaps formed from through-thickness cracks developed at the entry zone due to longitudinal tensile strain in that area. Other gaps, usually small, formed due to bending at the roll bite. The small gaps can become even narrower during passage through the roll gap. The gap between scale fragments is changed under the roll compression because of sliding and deformation of the oxide scale and metal extrusion through the gap. Crack closure eliminates or reduces the metal extrusion and improves the product's surface finish. It has been shown that among the main factors influencing the degree of metal extrusion during compression are the temperature and the initial width of the gap [41]. The scale slides at high temperatures making the initial gap smaller or closed. However, if the initial gap is relatively big the gap width is increased during the deformation.

\section{Numerical evaluation of IHTC during steel hot rolling - results and discussion}

As can be seen in Fig. 4, the apparent contact surface in the roll gap consists of the three types of zones: the roll and stock oxide scale zone, and two non-scaled zones forming

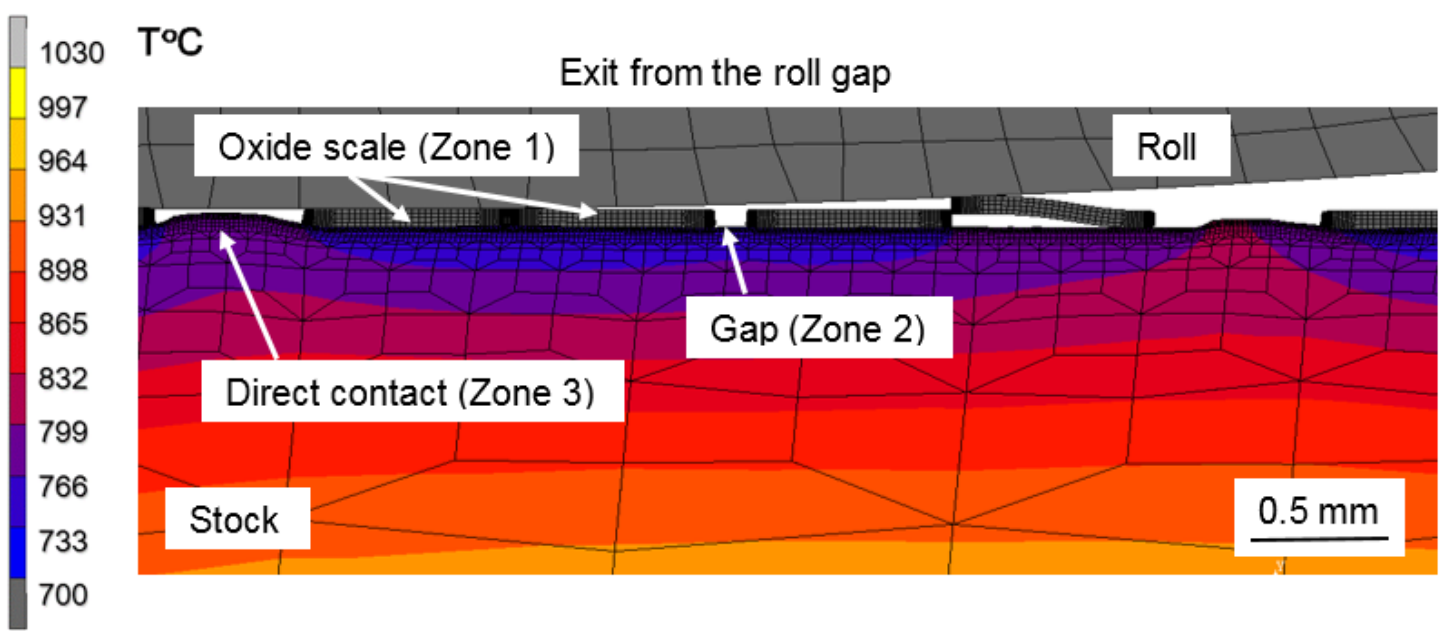

Fig. 4 Temperature and crack distribution predicted at the oxidized stock/roll interface at exit from the roll gap. 
gaps between stock scale fragments. Some gaps can have direct contact between the roll surface and extruded hot metal. This behaviour of the oxide scale and fresh steel allows for the assumption that there are three parallel channels (zones) for the heat from the high temperature stock to be transferred to the low temperature rolls. In the first zone, the heat is transported through the scale layer, the boundary gap due to partial contact between roll and scale and, possibly, the roll scale. In the second zone, the heat is transported through the boundary gap developed between the oxidised roll and the steel surface. The third zone is formed when the extruded metal has a direct contact with the relatively cold surface of the roll. In such a case, the heat is transferred through the gap as well as through the direct contact. The boundary gap due to partial contact between roll and the fresh metal is also assumed for the third zone. As can be seen (Fig. 4), the FE model results are in good agreement with the main representations of Prof. C.M. Sellars and his collaborators developed in the 1990s considering the several parallel heat flow systems at the oxidised rollstock interface. The advanced FE based model just allows for improvement of evaluation of the IHTC during metal forming operations assuming complexity of deformation in the area and evolving scale failure effects. The model has been upgraded with experimental data related to low carbon steel oxides obtained during hot tensile testing of the steel specimens of the following chemical content (wt \%): $0.18 \mathrm{C}, 0.26 \mathrm{Si}, 0.95 \mathrm{Mn}, 0.03 \mathrm{Cr}, 0.05 \mathrm{Ni}$ and $0.1 \mathrm{Cu}$. Matching the predicted and measured loads at the head of the specimen, as it is described elsewhere [42], the separation loads within the scale and at the scale/metal interface were implemented into the oxide scale model for evaluation of the IHTC. It is assumed in the model that the surface geometry of the roll does not change significantly during the rolling pass. The roll surface roughness is measured and included in the numerical analysis while the scale surface is assumed to be flat. The total thermal resistance, $R_{\ell}$, over the apparent contact area can therefore be determined as

$$
\frac{A_{a}}{R_{e}}=\frac{A_{1}}{R_{e 1}}+\frac{A_{2}}{R_{e 2}}+\frac{A_{3}}{R_{e 3}}
$$

where $A_{a}$ is apparent contact area and $A_{1}, A_{2}$ and $A_{3}$ are apparent areas occupied by the scale, gaps and extruded metal. $A_{1}=\sum_{i} A_{1 i}, i$ - number of the scale fragments; $A_{2}=\sum_{j} A_{2 j}, j-$ number of gaps and $A_{3}=\sum_{k} A_{3 k}, k$-number of the direct contact zones. Eq. (16) is similar to eq. (2) with the difference that the three heat flow channels are considered. The effective IHTC at the arc of contact is therefore determined as a sum of the heat transfer coefficients $C_{e i}$ determined within the corresponding zones

$$
C_{e}=C_{e 1} \alpha_{1}+C_{e 2} \alpha_{2}+C_{e 3} \alpha_{3}
$$

where $\alpha_{i}=A_{i} / A_{a}$ is the area fraction of the corresponding zones: the scale, the gap and the extruded metal zone, such that $\alpha_{1}+\alpha_{2}+\alpha_{3}=1$. Assuming no scale on the roll surface, the heat transfer coefficient through the scale (zone 1), $C_{e l}$, is determined as

$$
C_{e 1}=\frac{C_{o x} C_{b 1}}{C_{o x}+C_{b 1}}
$$

where $C_{o x}$ is the heat transfer coefficient through the oxide scale layer and $C_{b 1}$ is the heat transfer coefficient due to partial contact at the boundary gap (Fig. 5). This is usually called contact conductance. The heat transfer coefficient through the scale layer is determined as

$$
C_{o x}=\frac{k_{o x}(T)}{\delta_{o x}\left(p_{a}\right)}
$$


where $k_{o x}$ is the thermal conductivity of the scale depending on the temperature, $\mathrm{T}$, and $\delta_{o x}$ is the scale thickness, which depends on the pressure $p_{a}$. The temperature dependence of the thermal conductivity is calculated as

$$
k_{o x}(T)=1+7.833 \times 10^{-4} T
$$

within the temperature interval from $600^{\circ} \mathrm{C}$ to $1200^{\circ} \mathrm{C}$ [43]. In the case when the roll scale cannot be neglected in terms of the heat transfer, the eq. (11) can be rewritten as

$$
C_{e 1}=\frac{C_{o x} C_{b 1} C_{R o x}}{C_{R o x} C_{o x}+C_{R o x} C_{b 1}+C_{o x} C_{b 1}}
$$

where $C_{R o x}$ is the heat transfer coefficient through the roll scale layer determined as

$$
C_{R o x}=\frac{k_{R o x}(T)}{\delta_{R o x}\left(p_{a}\right)}
$$

where the parameters $k_{R o x}$ and $\delta_{R o x}$ have the same meaning as in the eq. (16) but related to the roll's oxide scale. The contact conductance parameter, $C_{b 1}$, has proved to be difficult to determine. No systematic measurements or analyses have been found for the quantitative variations with surface, interface and deformation conditions during metal forming conditions. It has been assumed that the contact conductance, in addition to the effects of the surface roughness and the thermal conductivity of two contacting materials, is related to the apparent contact pressure $p_{a}$ and the hardness, $H V$, of the softer material in the contact, as it was adopted earlier by Li and Sellars [31] and expressed by eq. (11) - (14).

For zone 2, when there is no direct contact between solids, the heat transfer coefficient $C_{e 2}$ depends on the roll oxide thickness, lubricant thermal conductivity and other parameters. It was assumed to be negligibly small in this analysis. For zone 3, the heat transfer coefficient $C_{e 3}$ is determined as

$$
C_{e 3}=C_{b 3} \beta_{s}+C_{e 2}\left(1-\beta_{s}\right)
$$

where $\beta_{s}$ is the degree of the fresh steel contact. The contact conductance $C_{b 3}$ between extruded fresh steel and the roll surface is determined from eq. (9) and (12), assuming $A_{3}=$ 0.405 and $B_{3}=1.5$. The harmonic mean of the thermal conductivity of the roll and specimen steel, $k_{h 3}$, is determined as shown in eq. (2). The Vickers hardness of the fresh plain carbon steel, $H V_{3}$, is calculated approximately by using the flow stress $\sigma_{s}$ at $8 \%$ strain, neglecting work hardening [44]:

$$
H V_{3}=3 \sigma_{s}
$$

The degree of the fresh steel contact $\beta_{s}$ is determined as the ratio between the length of the fresh steel contact and the length of the gap in the oxide scale formed at the arc of contact during the rolling pass (Fig. 5). It has to be noted that the parameter $\beta_{s}$ is changed during the rolling pass depending on many technological parameters such as temperature, scale thickness, chemical composition of the steel, gap width at entry into the roll gap, rolling

$T^{\circ} \mathbf{C}$
1006
910
815
719
624
528
432
336
241
145
50

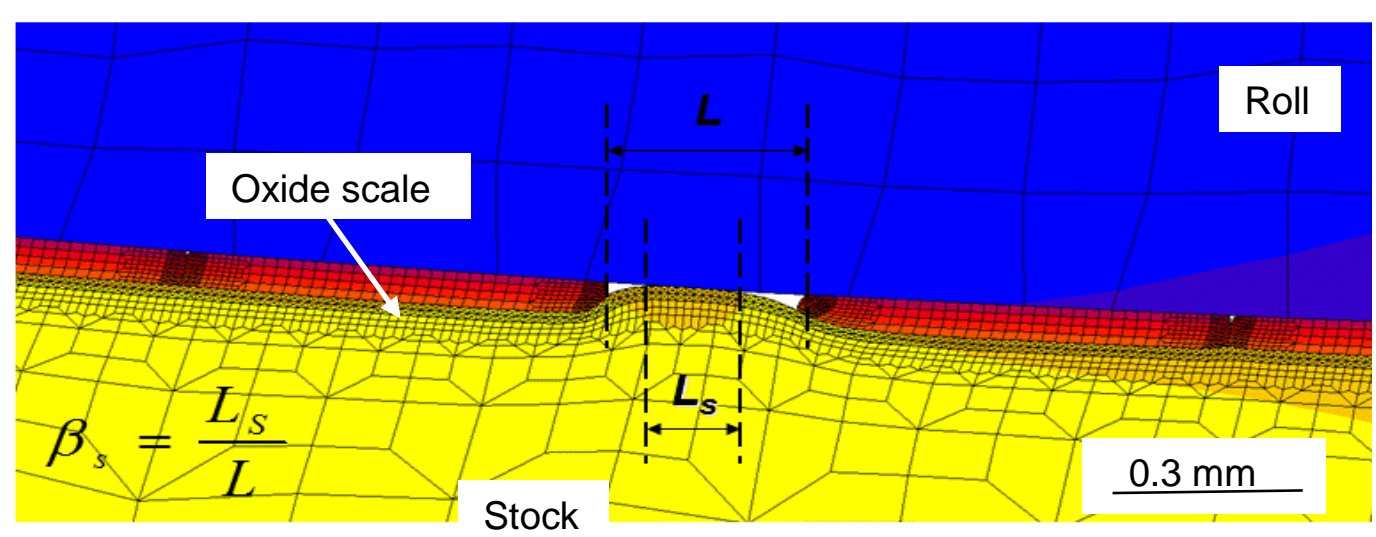

Fig. 5 Temperature distribution predicted at the area of the fresh steel contact with the roll surface. 
reduction, etc. The area fraction $\alpha_{i}$ of the corresponding zones the scale $(i=1)$, the gap $(i=2)$ and the extruded metal zone $(i=3)$ is changed during the rolling pass and depends, among others, on the initial stock temperature and the oxide scale thickness, as can be seen in Fig. 6 . The gaps within the oxide scale are formed at lower temperatures and higher reductions. It can be explained by the fact that the scale /metal interface of the low carbon steel becomes weaker at higher temperatures and the scale tends to slide along the interface rather than cracking in the through-thickness mode. Thicker scale, of about $100 \mu \mathrm{m}$ thickness for instance, exhibits more tendency towards crack development during the rolling pass rather than thinner scale layers about $10-30 \mu$ m thick.

The heat transfer coefficient through the scale layer, $C_{o x}$, is also changed during the rolling pass, mainly because of changes in the thermal conductivity of the scale, $k_{o x}$, and the scale thickness, $\delta_{o x}$, depending on the temperature, type of the oxide scale and the rolling reduction (Fig. 7). As can be seen in Fig. 7a-b, the thickness of the oxide scale changes during the rolling pass according to the reduction. The changes are more pronounced when the scale consists of a few sublayers and big voids, which are closed at the initial deformations during the rolling pass. 

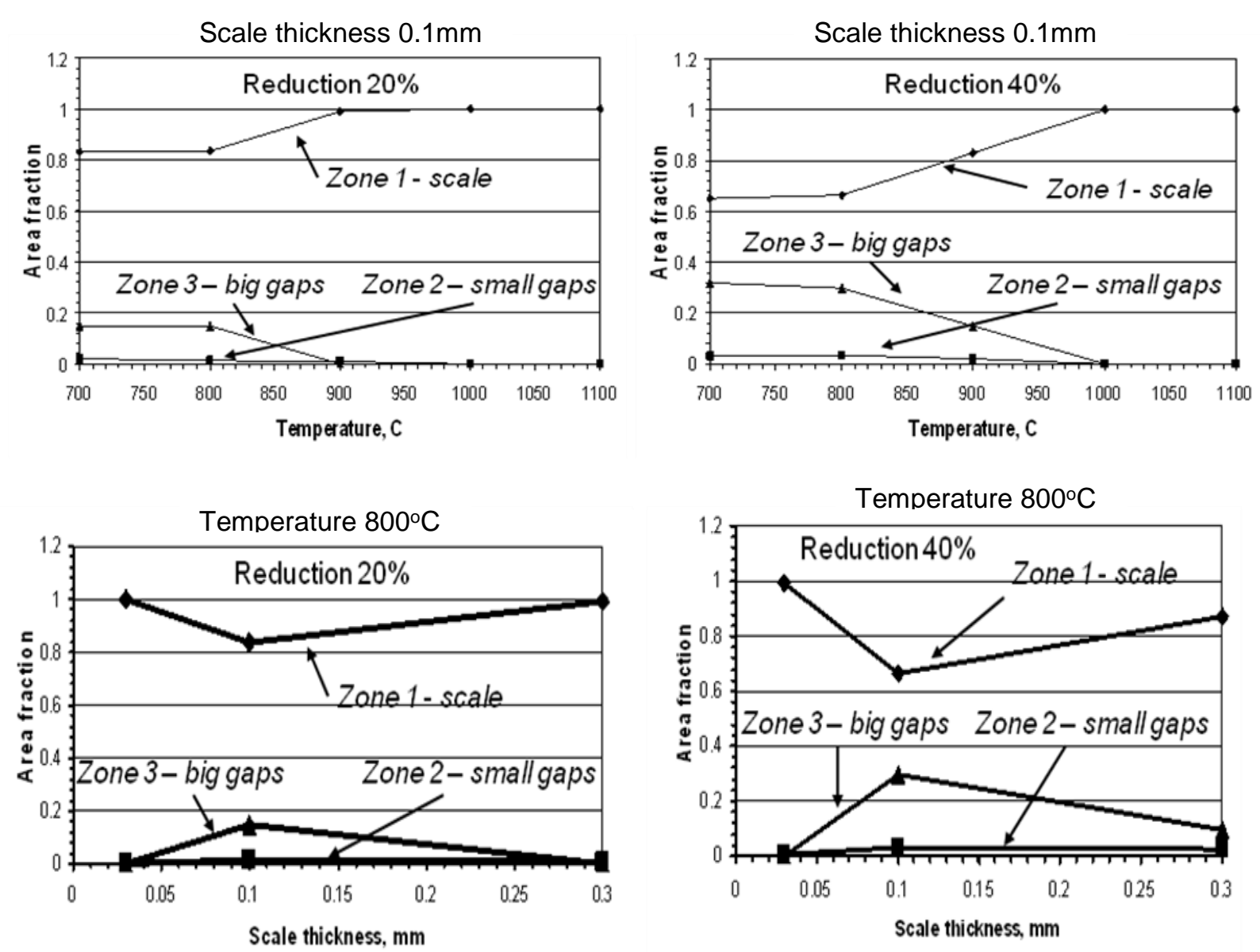

Fig. 6 Effect of the initial stock temperature and oxide scale thickness on the area fraction of the scale failure zones predicted for the different rolling reductions.

These changes will affect the heat transfer coefficient through the oxide scale layer according to eq. (19). The degree of fresh steel contact, $\beta s$, is changed during the rolling pass due to steel extrusion within the gap between the scale fragments and among other rolling parameters, such as the scale thickness and temperature, depends to a large extent on the initial gap width
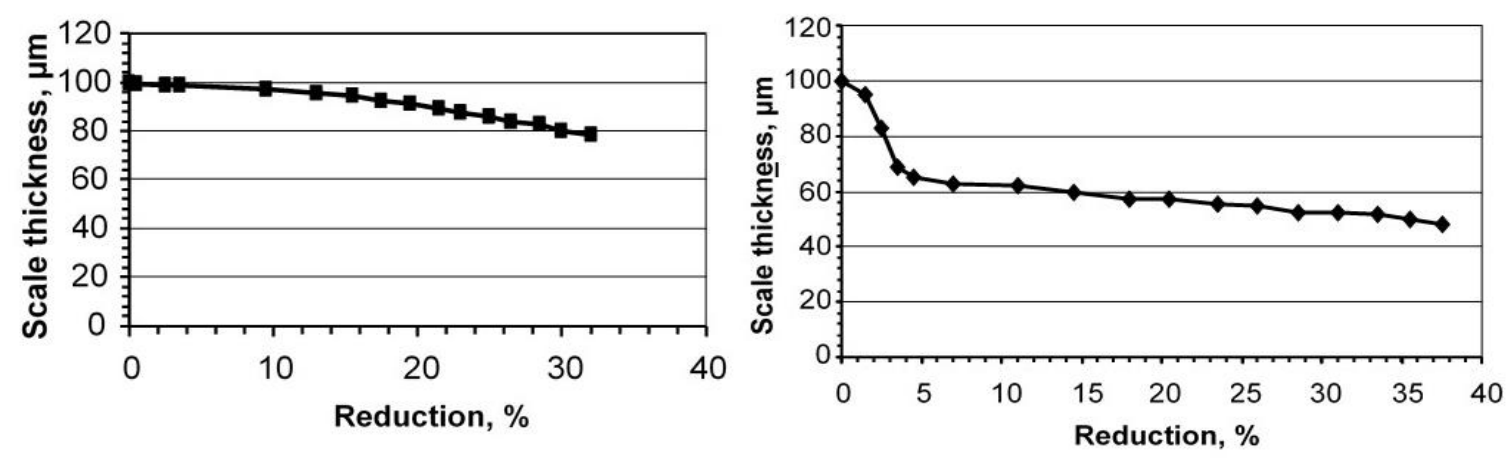

Fig. 7 The oxide scale thickness predicted for the different reductions during the rolling pass: a - one layer oxide scale, no big voids; $b$ - three layer oxide scale, big voids 
at entry into the roll gap and the rolling reduction. As can be seen in Fig 8a, the small gaps, formed presumably due to bending at the roll bite, tend to close during further compressive deformation within the arc of contact during a rolling pass and there is no contact between the roll surface and fresh stock steel observed. As the initial gap becomes wider, the gap narrows until about $10 \%$ reduction. Then, at higher reductions, the gap widens, allowing fresh steel to be extruded into the gap under the roll pressure. The first direct contact between fresh steel and the roll surface occurs at about 20-30\% reduction, depending on the initial gap width, and the degree of fresh steel contact increases up to a fraction of about $0.5-0.8$ at $40 \%$ reduction (Fig. $8 \mathrm{~b}-\mathrm{f}$ ). These changes in the degree of fresh steel contact lead to significant changes in the ITHC calculated for the different reductions, as shown in Table 3.
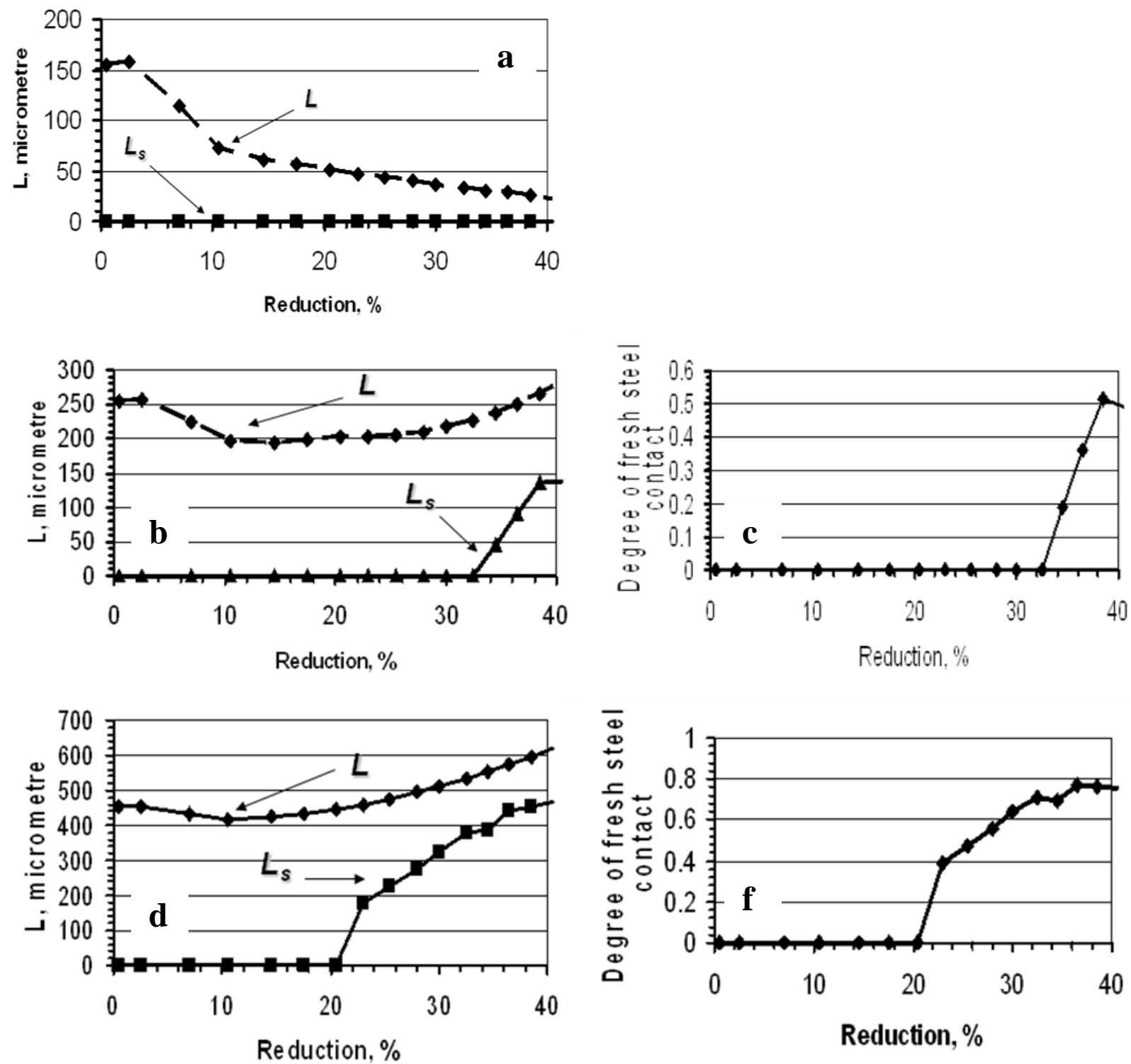

Fig. 8 Effect of the rolling reduction on the gap width $L(a, b, d)$ and degree of fresh steel contact $\beta_{s}(\mathrm{c}, \mathrm{f})$ predicted for the different gap width at entry into the rolling pass and the initial temperature $T=1000^{\circ} \mathrm{C}$. 
Table 3. Effect of the rolling reduction and the initial oxide scale thickness on IHTC predicted at the initial temperature of $800^{\circ} \mathrm{C}$

\begin{tabular}{|c|c|c|}
\hline $\begin{array}{c}\text { Rolling reduction, } \\
\%\end{array}$ & $\begin{array}{c}\text { Initial scale thickness, } \\
\mathbf{m m}\end{array}$ & $\begin{array}{c}\mathbf{I H T C}, \\
\mathbf{k W} / \mathbf{m}^{\mathbf{2}} \mathbf{K}\end{array}$ \\
\hline 20 & 0.03 & 56 \\
\hline 20 & 0.1 & 22 \\
\hline 30 & 0.03 & 128 \\
\hline 30 & 0.11 & 52 \\
\hline 40 & 0.03 & 153 \\
\hline 40 & 0.1 & 138 \\
\hline
\end{tabular}

Quantitative characterization of heat transfer at the workpiece/tool interface during hot metal forming operations is still inconsistent and in most cases creates a major handicap to producing accurate and reliable models for hot metal working processes. The reason for this is partly because of the complicated physical phenomena taking place in the contact. Along with complicated secondary oxide scale behaviour, the importance of surface roughness and lubrication effects on IHTC in the hot rolling of steel has been widely recognized [45]. The strain imposed on the steel surface when stock enters the roll gap, because of drawing in by frictional contact with the roll, produces longitudinal tensile stresses ahead of the arc of contact, which may result in oxide failure. The fractured scale, which has a thermal conductivity about 10-15 times less than the steel, can enable direct contact of hot metal with the cold roll due to extrusion through fractured scale up to the cool roll surface [46]. Such spaces, distributed along the arc of contact, will increase the IHTC through the oxide thermal barrier, as discussed above. However, at higher temperatures the oxide metal interface is weaker than the oxide and shear stresses cannot be fully transmitted to the oxide raft due to sliding, which complicates the crack pattern formation [47]. The location of the plane of sliding is determined by the cohesive strength at the different interfaces within the steel-inhomogeneous oxide scale and by the stress distribution when delamination within the scale takes place. A major problem is high sensitivity of properties and morphology of both the scale itself and the interfaces to the chemical content of steel and the conditions of their growth. Despite considerable complexity, a combination of careful experiments and detailed finite element (FE) analysis has been successfully applied to represent a wide range of the observed physical phenomena [48] and numerical characterization of these phenomena can be achieved using the physically-based FE model briefly described in this section. Although the results presented above are mainly for carbon steels, the method can be applied to other technologically important alloys such as stainless steels and aluminium alloys.

\section{Conclusion}

To a large extent, the success of any mathematical model depends on the appropriate formulation of the boundary conditions, which, as seen from the evaluation of IHTC, could be as sophisticated as the model itself. The method described, based on FE modelling, allows for calculation of the IHTC at the stock/roll interface assuming the effects of failure of secondary oxide scale. Comparing the results in Figs. 2 and 9, it can be suggested that including all of the mentioned complexities into a single mathematical model describing dependence of IHTC is time consuming and not always necessary. Instead, relatively simple formulae for heat transfer work well for general applications based on understanding and 
predicting the micro events at the roll/stock interface affecting the IHTC, such as those suggested by Prof. C.M. Sellars and his collaborators in the 1990s. Of course, reasonable choices are necessary to achieve desirable precision; they should take into consideration the most important dependencies that affect the tribological system. Sellars was adept at such choices thanks to the tremendous physical insight that characterised his research.

\section{Acknowledgement}

The authors would like to express their deep gratitude to Professor Christopher Michael (Mike) Sellars (deceased) for his leadership, teaching and companionship over many years of research together. Mike was a researcher of great insight, effortlessly blending scientific rigour with industrial relevance to produce results of importance and value to both the academic and industrial communities around the world. The contribution of Dr Y.H. Li from GE Energy Management UK and the support from the National Science Centre Poland (grant no. DEC-2013/09/B/ST8/00141) are highly appreciated.

\section{Literature}

1. J.A. Schey, Metal deformation processes: friction and lubrication, Marcel Dekker, New York, 1970

2. J.A. Schey, Tribology in Metalworking, Friction, Lubrication and Wear, The American Society for Metals, Metals Park, Ohio, 1983

3. J.H. Beynon, Modelling of friction and heat transfer during metal forming, KomPlasTech'99, 17-20 January, (Szczyrk, Poland), 1999, p 47-54

4. B.K. Chen, P.F. Thomson and S.K. Choi, Temperature distribution in the roll-gap during hot flat rolling, J. Mater. Proc. Technol., Vol. 30, 1992, p 115-130

5. S.P. Timothy, H.L. Yiu, J.M. Fine and R.A. Ricks, Simulations of single pass of hot rolling deformation of aluminium alloy by plane strain compression, Mat. Sci. Tech., Vol. 7, 1991, p 255-261

6. S.L. Semiatin, E.W. Collings, V.E. Wood and T. Altan, Determination of the interface heat transfer coefficient for non-isothermal bulk forming process, Trans. ASME, J. Eng. Ind., Vol. 109, 1987, p 49-57

7. M. Pietrzyk, J.G. Lenard, A study of thermal mechanical modelling of hot flat rolling, $J$. Mater. Shaping Technol., Vol. 7, 1989, p 117-126

8. C.O. Hlady, I.V. Samarasekera, E.B. Hawbolt and J.K. Brimacombe, Heat transfer in the hot rolling of aluminium alloys, Int. Symp. On Light Metals Processing and Applications; $32^{\text {nd }}$ Annual Conf. of Metallurgists CIMM, Bickert C. et.al., Eds., 1993, p 511-522

9. C.O. Hlady, J.K. Brimacombe, I.V. Samarasekera and E.B. Hawbolt, Heat transfer in the hot rolling of metals, Met. \& Mat. Trans. B., Vol. 26B, 1995, p 1019-1027

10. Y.H. Li, C.M. Sellars. Evaluation of interfacial heat transfer and its effects on hot forming processes. Ironmaking Steelmaking, 23 (1996), p 58-61

11. M. Pietrzyk, C. Roucoules and P.D. Hodgson, Modelling the thermomechanical and microstructural evolution during rolling of a Nb HSLA steel, ISIJ Int. 35 (5) (1995), p $531-541$

12. H. Dyja and P. Korczak, The thermal-mechanical and microstructural model for fem simulation of hot plate rolling, J. Mater. Process. Technol. 92-93 (1999) 463-467 
13. M.P. Phaniraj, B.B. Behera and A.K. Lahiri, Thermo-mechanical modelling of two phase rolling and microstructure evolution in the hot strip mill. Part 1. Prediction of rolling loads and finish rolling temperature, J. Mater. Proc. Technol., Vol. 170, 2005, p 323-335

14. Z. Malinowski, J.G. Lenard and M.E. Davies, A study of heat transfer coefficient as a function of temperature and pressure, J. Mater. Proc. Technol., Vol. 41, 1994, p 125-142

15. M. Pietrzyk and J.G. Lenard, A study of boundary conditions in hot/cold flat rolling, Int. Conf. Computational Plasticity: Models, Software and Applications, Proceedings, D.R.J. Owen et al., Eds., (Wales), Pineridge Press, 1989, p 947-958

16. W.C. Chen, I.V. Samarasekera and E.B. Hawbolt, Characterisation of the thermal field during rolling of microalloyed steels. $33^{\text {rd }}$ Mechanical Working and Steel Processing Conf., Proceedings, Vol. XXIX, (USA), Iron \& Steel Soc., 1992, p 349-357

17. P.G. Stevens, K.P. Ivens and P. Harper, Increasing work-roll life by improved rollcooling practice, J. Iron Steel Inst., Vol. 209, 1971, p 1-11

18. K. Murata, H. Morise, M. Mitsutsuka, H. Haito, T. Kumatsu and S. Shida, Heat transfer between metals in contact and its application to protection of rolls, Trans. ISIJ, Vol. 24, 1984, p B309

19. C.M. Sellars, Computer modelling of hot working processes, Mat. Sci. Tech., Vol. 1, 1985, p 325-332

20. X. Duan and T. Sheppard, Influence of forming parameters on static recrystallization behaviour during hot rolling aluminium alloy 5083, Modelling Simul. Mater. Sci. Eng. Vol. 10, 2002, p 363-380

21. Y. Kang, Y. Liu and Y. He, An experimental and numerical study of heat transfer coefficient in deformation zone during hot rolling of aluminium alloy, Proc. Int. Conf. on Mechanic Automation and Control Engineering (MACE), 26-28 June 2010, Wuhan, Publ. IEEE, 2010, p 5789-5791

22. A. Saxena and Y Sahai, Modeling of fluid flow and heat transfer in twin-rolled casting of aluminium alloys, Materials Transactions, Vol. 43, No. 2, 2002, p 206-213

23. T. Yoneyama, H. Asaoka, H. Kimura, I. Hoshino and M. Kokubo, Heat transfer and roll surface temperature in the hot rolling of aluminium sheet, Journal of Tribology, Vol 121, 1999, p 753-760

24. W.C. Chen, I.V. Samarasekera, A. Kumar, E.B. Hawbolt, Mathematical modeling of heat flow and deformation during rough rolling, Ironmaking and Steelmaking, Vol. 20(2), p 113-125

25. T. Wanheim and N. Bay, A model for friction in metal forming processes, Ann. CIRP, Vol. 27 (1), 1978, p 189-193

26. C. Devadas, I.V. Samarasekera and E.B. Hawbolt, The thermal and metallurgical state of steel strip during hot rolling: Part 1, Characterization of heat transfer, Metall. Trans. A., Vol. 22A, 1991, p 307-319

27. W.C. Chen, I.V. Samarasekera and E.B. Hawbolt, Fundamental Phenomena Governing Heat Transfer During Rolling, Metall. Trans. A, Vol. 24A, 1993, p 1307-1320

28. J.G. Lenard, Measurements of Friction and in Cold Flat Rolling, J. Mater. Shaping Technol., Vol. 9, 1991, p 171-180 
29. J. Ball, J.A. Treverton and M.C. Thornton, Evaluation of the effects of stresses in hot rolling mills on oxide films on aluminium, J. Soc. Trib. Lub. Engrs., Vol. 50, 1994, p 8993

30. Y.H. Li and C.M. Sellars, Comparative investigations of interfacial heat transfer behaviour during hot forging and rolling of steel with oxide scale formation, J. Mater. Proc. Technol., Vols. 80-81, 1998, p 282-286

31. Y.H. Li and C.M. Sellars, Modelling deformation behaviour of oxide scales and their effects on interfacial heat transfer and friction during hot steel rolling, $2^{\text {nd }}$ Int. Conf. On Modelling of Metal Rolling Processes, Proceedings, J. H. Beynon, P. Ingham, H. Teichert and K. Waterson, Eds., (London, UK), The Institute of Materials, 1996, p 192-206

32. M.G. Cooper, B.B. Mikic and M.M. Yovanovich, Thermal contact resistance, Int. Heat Mass Transfer, Vol. 12, 1969, 279-300

33. M. Bahrami, J. R. Culham, M. M. Yovanovich, and G. E. Schneider, Thermal Contact Resistance of Nonconforming Rough Surfaces Part 1: Contact Mechanics Model, Journal of Thermophysics and Heat Transfer, Vol. 18, No. 2, 2004, p 209 - 217

34. M. Williamson and A. Majumdar, Effect of surface deformations on contact conductance, Trans. ASME: J. Heat Transfer, Vol. 114, Nov. 1992, 802-809

35. J. Pullen and J.B.P. Williamson, On the Plastic Contact of Rough Surfaces, Proc. R. Soc. London, Ser. A, A327, 1972, 159-173

36. B.B. Mikic, Thermal contact conductance: theoretical considerations, Int. J. Heat Mass Transfer, Vol. 17, 1974, 205-214

37. G.V. Samsonov, The Oxide Handbook, IFI/Plenum, New York, 1973

38. M. Krzyzanowski, W.M. Rainforth, Oxide modelling in hot rolling: assumptions, numerical techniques, examples of predictions, Ironmaking \& Steelmaking, 37, No 4, 2010, 276-282

39. M. Krzyzanowski, J.H. Beynon and C.M. Sellars, Analysis of secondary oxide scale failure at entry into the roll gap Metallurgical and Materials Transactions B, Vol. 31B (2000) 6, 1483-1490

40. M. Krzyzanowski, P. Suwanpinij, J.H. Beynon, Analysis of crack development, both growth and closure, in steel oxide scale under hot compression, Materials Processing and Design: Modelling, Simulation and Applications, NUMIFORM 2004, (eds S. Ghosh, J.C. Castro and J.K. Lee), American Institute of Physics, 712, Melville, New York, 2004, 1961-1966

41. J.H. Beynon, M. Krzyzanowski, N. Taranets, Surface scale evolution in the hot rolling of steel, Invited Keynote at "HSLA Steels 2005 and ISUGS 2005", 8-10 November, Sanya, Hainan, China, Proceedings of $5^{\text {th }}$ International Conference on HSLA Steels "HSLA Steels 2005”, Iron and Steel Supplement, 40, 2005, 83-90

42. M. Krzyzanowski, J. H. Beynon, Measurement of oxide properties for numerical evaluation of their failure under hot rolling conditions, Journal of Materials Processing Technology, vol. 125-126, 2002, 398-404

43. H. Ranta, J. Larkiola, A.S. Korhonen, A. Nikula, A Study of Scale-Effects During Accelerated Cooling, Proc. $1^{\text {st }}$ Int. Conf. on 'Modelling of metal rolling processes', September 1993, London, UK, The institute of Materials, UK, 1993, 638-649

44. D. Tabor, The Hardness of Metals, Clarendon Press, Oxford, 1951 
45. M. Krzyzanowski and J.H. Beynon, Oxide behaviour in hot rolling, in Metal Forming Science and Practice, (ed J.G. Lenard), Elsevier, 2002, pp. 259-295

46. Beynon, J.H. (1998) The impact of tribological issues of energy conservation in metal forming operations, Proceedings of the $24^{\text {th }}$ Leeds-Lyon Symposium on Tribology, (ed D. Dowson), Elsevier Science BV, London, pp. 327-33

47. M. Krzyzanowski and J.H. Beynon, The tensile failure of mild steel oxides under hot rolling conditions, Steel Research, 70 (1), 1999, 22-27

48. M. Krzyzanowski and J.H. Beynon, Modelling the Behaviour of Oxide Scale in Hot Rolling, ISIJ International, Vol. 46(11), 2006, p 1533-1547 